\title{
A study of the properties of metal packaging materials using model corrosive media
}

\author{
O.V. Bessarab,* T.F. Platonova and I.V. Protunkevitch \\ Russian Research Institute of Canning Technology - Branch of V.M. Gorbatov Federal \\ Research Center for Food Systems of the RAS, Shkolnaya st., 78, Vidnoe place, Leninskiy \\ district, Moscow region, 142703 Russian Federation \\ *E-mail: upakovka@vniitek.ru
}

\begin{abstract}
Internal corrosion of metal cans is one of factors that affect the quality of canned food during the storage period. Thus, one should take into account the corrosivity of canned products when choosing the metal packaging. To rationalize corrosion tests, it is advisable to replace food products with model media. However, it should take into account that the corrosivity of a model medium and a product may be different due to the presence of substances that affect the corrosion rate in the products. The purpose of this work was to study the corrosion kinetics of tinplate in one- and two-component model media containing oxalic and citric acids, as well as in tomato paste mixed with water. The tinplate uniform corrosion rate was measured by the polarization resistance method. The tinplate pitting corrosion rate was measured by the zeroresistance amperometry method. The measurements were performed in automatic mode using an Expert-004 corrosion meter. The results indicated that a solution containing $0.40 \%$ citric acid and $0.30 \%$ oxalic acid should be used as a model corrosive medium that simulates canned vegetables because it is the most corrosive. The corrosion kinetics tinplate in contact with tomato paste is similar to the corrosion kinetics in the two-component model medium. At the same time, the corrosivity of tomato paste toward tinplate is 2.4 times smaller than that of the model medium (8.54 and $20.46 \mu \mathrm{m} /$ year, respectively).
\end{abstract}

Keywords: tinplate, model medium, citric acid, oxalic acid, tomato paste, corrosion rate, uniform corrosion, pitting corrosion, polarization resistance method, zero-resistance amperometry method, Expert-004 corrosion meter, canned vegetable food.

Received: July 8, 2020. Published: July 21, 2020

doi: $\underline{10.17675 / 2305-6894-2020-9-3-7}$

\section{Introduction}

The corrosion resistance of the inner surfaces of metal packaging is one of the factors that affect the canned food quality in the course of storage. Canned food components such as organic acids, their salts, and food salt cause electrochemical corrosion of tinplate that results in migration of metal ions into the product. When electrolytes contact the metal package inner surface, an electrochemical corrosion process occurs at the interface, in which reactions of metal anodic oxidation and electrolyte cathodic reduction occur simultaneously, resulting in the transfer of metal ions into the product [1]. Thus, during the storage of canned food in 
tin packaging, salts of metals, mainly tin and iron, accumulate, which leads to deterioration of the canned food consumer properties [2,3]. Thus, the corrosion stability of the material should be taken into account when choosing the metal packaging.

To rationalize the corrosion tests of metal packaging and packaging materials, it is expedient to replace food products with model media, i.e., water solutions containing corrosive substances. This approach provides a number of advantages:

- it simplifies the procedure for laboratory test preparation;

- it reduces the time and material costs for testing;

- it ensures reproducibility of results because the model media have a stable chemical composition.

In previous years, our institute's packaging laboratory developed a canned fruit and vegetables classification depending on their corrosivity (Tables 1 and 2) [4-6].

Table 1. Canned food classification according to their corrosivity.

\begin{tabular}{ccc}
\hline & \multicolumn{2}{c}{ Corrosive components } \\
\cline { 2 - 3 } Groups & Food salt, \% & $\begin{array}{c}\text { Titrated acidity (in terms of malic } \\
\text { acid), \% }\end{array}$ \\
\hline Low corrosivity & $<1.0$ & $<0.2$ \\
Moderate corrosivity & $1.0-2.0$ & $0.2-1.0$ \\
Strong corrosivity & $>2.0$ & $>1.0$ \\
\hline
\end{tabular}

Table 2. Corrosivity of canned food and corrosion stability of metal packaging.

\begin{tabular}{|c|c|c|}
\hline $\begin{array}{l}\text { Degree of canned food } \\
\text { corrosivity }\end{array}$ & $\begin{array}{l}\text { Corrosion rate according to } \\
\text { gravimetric data, } \mathrm{mg} /\left(\mathbf{m}^{2} \cdot \text { hour }\right)\end{array}$ & $\begin{array}{c}\text { Corrosion stability of metal } \\
\text { packaging }\end{array}$ \\
\hline Low corrosivity & $0.3-2.0$ & Stable \\
\hline Moderate corrosivity & $2.0-4.0$ & Low-stable to stable \\
\hline Strong corrosivity & $4.0-7.5$ & Low-stable \\
\hline
\end{tabular}

This classification does not take into account the chemical nature of acids that canned food contains, as well as the presence of substances that are inhibitors and catalysts of corrosion in the products.

It is known from literature $[7,8]$ that anthocyanin pigments can form complexes with tin ions, which leads to cathodic depolarization and, as a result, an increase in tin migration from the metal surface to the product. The presence of nitrate ion in products due to the presence of residual amounts of pesticides has a catalytic effect on tin migration, too $[9,10]$. The presence of copper ions also has a catalytic effect [10]. 
Gelatin and pectin have an inhibiting effect on corrosion. Their action is based on the adsorption of conglomerates on the metal surface and, as result, formation of a protective film $[11,12]$. Moreover, some reducing agents (antioxidants) contained in the products, such as sorbic and benzoic acids, their salts (sorbates and benzoates), as well as some amino acids, have an inhibitory effect [13-15].

Due to the presence of substances in canned products, such as pectin substances, pigments, and sugars, that affect the corrosion rate, the corrosivity of a product and a model medium may differ significantly. Thus, to interpret the corrosion tests results accurately, it is of interest to establish the relationship between the corrosion kinetics of tinplate in model media and it products.

Citric acid was chosen as the main component of the model corrosive media as the most common component as it is found in almost all types of vegetable raw products (up to $0.5 \%$ ) and is also widely used as a treatment additive. Furthermore, the composition of canned vegetables includes oxalic acid, mainly in the form of oxalates. The highest content of oxalates (1.0-4.0\%) occurs in various spices, such as cumin, cardamom, ginger, etc. [16]. Tomatoes, eggplants, broccoli, carrots, potatoes, celery, sweet peppers, and beans contain up to $0.1 \%$ oxalates. The most common canned foods containing oxalic acid include tomato paste, canned tomatoes, canned vegetables and fish in tomato sauce, as well as foods containing various spices.

The purpose of this work was to study the corrosion kinetics of tinplate in tomato paste and in model corrosive media containing citric and oxalic acids.

\section{Experimental}

In this work, we used the following model corrosive media:

- $0.25-1.00 \%$ oxalic acid aqueous solutions;

- $0.25-1.50 \%$ citric acid aqueous solutions;

- aqueous solutions containing a mixture of citric and oxalic acids;

- tomato paste (dry matter: 25-28\%) mixed with water in a ratio of 1:4 by weight.

The uniform corrosion rate $(K)$ was determined by the polarization resistance method using a two-electrode scheme. The method involves the creation of a constant potential difference (external polarization) between two identical metal plates serving as electrodes, and measuring the parameters of the current that occurs in this case. The rate of pitting corrosion $(P)$ was determined by zero-resistance amperometry based on measuring the current density flowing between two electrodes without external polarization, i.e., in a spontaneous process. We performed measurements using an Expert-004 microprocessorbased versatile automatic corrosion meter $[17,18]$.

We performed experiments by the methodology developed at our institute [19, 20]. The duration of one experiment was 160-168 hours; the corrosion rate values were recorded automatically every 4 hours. In this work, we used a glass electrochemical cell containing two identical metal plates (electrodes), two sealing gaskets made of a polymer material 
(plastisol) and a fastening accessory. The cell was made of heat-resistant glass and had the form of an open cylinder on both sides with a neck for filling. The fastening accessory consisted of two rectangular plates made of hard plastic, connected by two screws. The electrodes were made of white tinplate samples with $2.7-2.9 \mathrm{~g} / \mathrm{m}^{2}$ (First class according to GOST 13345; hereinafter-tinplate I) or $5.5-5.7 \mathrm{~g} / \mathrm{m}^{2}$ (Second class according to GOST 13345; tinplate II) tin coating on the surface in contact with the medium.

Based on the measurements results, we built plots that reflected the corrosion process kinetics, i.e., the change in the uniform corrosion rate and pitting corrosion rate of the tinplate during the experiment. Based on the analysis of the plots, we calculated the average steadystate corrosion rate of tinplate, which characterizes the corrosivity of the medium. We calculated the average steady-state value of the uniform corrosion rate using the formula:

$$
\bar{K}_{\mathrm{st}}=\frac{\sum_{i=1}^{n} K_{i}}{n}
$$

where $\bar{K}_{\text {st }}$ is the average steady-state value of the uniform corrosion rate, $\mu \mathrm{m} /$ year; $K_{i}$ is the value of the uniform corrosion rate measured in the steady-state mode, $\mu \mathrm{m} /$ year; and

$n$ is the number of measurements of the uniform corrosion rate in the steady-state mode.

We calculated the average steady-state pitting corrosion rate using the formula:

$$
\bar{P}_{\mathrm{st}}=\frac{\sum_{i=1}^{n} P_{i}}{n}
$$

where $\bar{P}_{\text {st }}$ is the average steady-state value of the pitting corrosion rate, $\mu \mathrm{m} /$ year; $P_{i}$ is the pitting corrosion rate measured in the steady-state mode, $\mu \mathrm{m} / \mathrm{year}$; and $n$ is the number of measurements of the pitting corrosion rate in the steady-state mode.

We calculated the mean square deviation of the measurement results of the steady-state uniform corrosion rate using the formula:

$$
S_{\mathrm{K}}=\sqrt{\frac{\sum_{i=1}^{n}\left(\bar{K}_{\mathrm{st}}-K_{i}\right)^{2}}{n-1}}
$$

where $S_{\mathrm{K}}$ is the average square deviation of the measurement results, $\mu \mathrm{m} /$ year; $\bar{K}_{\text {st }}$ is the average stationary value of the uniform corrosion rate, $\mu \mathrm{m} /$ year; $K_{i}$ is the uniform corrosion rate measured in the steady-state mode, $\mu \mathrm{m} / \mathrm{year}$; $n$ is the number of measurements of the uniform corrosion rate in the steady-state mode.

We calculated the mean square deviation of the measured steady-state pitting corrosion rate using the formula:

$$
S_{\mathrm{P}}=\sqrt{\frac{\sum_{i=1}^{n}\left(\bar{P}_{\mathrm{st}}-P_{i}\right)^{2}}{n-1}}
$$


where $S_{\mathrm{P}}$ is the average square deviation of the measurement results, $\mu \mathrm{m} / \mathrm{year}$; $\bar{P}_{\text {st }}$ is the average steady-state pitting corrosion rate, $\mu \mathrm{m} /$ year;

$P_{i}$ is the pitting corrosion rate measured in the steady-state mode, $\mu \mathrm{m} / \mathrm{year}$;

$n$ is the number of measurements of the pitting corrosion rate in the steady-state mode.

For two-component corrosive media, we calculated the additive steady-state uniform corrosion rate using the formula:

$$
K_{\mathrm{a}}=\frac{\omega_{\mathrm{c}} \cdot \bar{K}_{\mathrm{c}}+\omega_{\mathrm{o}} \cdot \bar{K}_{\mathrm{o}}}{\omega_{\mathrm{c}}+\omega_{\mathrm{o}}}
$$

where $K_{\mathrm{a}}$ is the additive steady-state uniform corrosion rate for a two-component solution, $\mu \mathrm{m} /$ year;

$\bar{K}_{\mathrm{c}}$ is the average steady-state rate of uniform corrosion in citric acid solution, $\mu \mathrm{m} / \mathrm{year}$;

$\bar{K}_{\mathrm{o}}$ is the average steady-state rate of uniform corrosion in oxalic acid solution, $\mu \mathrm{m} /$ year;

$\omega_{\mathrm{c}}$ is the mass fraction of citric acid in the solution, \%;

$\omega_{\mathrm{o}}$ is the mass fraction of oxalic acid in the solution, $\%$.

We calculated the additive steady-state rate of pitting corrosion using the formula:

$$
P_{\mathrm{a}}=\frac{\omega_{\mathrm{c}} \cdot \bar{P}_{\mathrm{c}}+\omega_{\mathrm{o}} \cdot \bar{P}_{\mathrm{o}}}{\omega_{\mathrm{c}}+\omega_{\mathrm{o}}}
$$

where $P_{\mathrm{a}}$ is the additive value of steady-state pitting corrosion rate in the two-component solution, $\mu \mathrm{m} /$ year;

$\bar{P}_{\mathrm{c}}$ is the average steady-state rate of pitting corrosion in the citric acid solution, $\mu \mathrm{m} / \mathrm{year}$;

$\bar{P}_{\mathrm{o}}$ is the average steady-state rate of pitting corrosion in the oxalic acid solution, $\mu \mathrm{m} / \mathrm{year}$;

$\omega_{\mathrm{c}}$ is the mass fraction of citric acid in the solution, \%;

$\omega_{\mathrm{o}}$ is the mass fraction of oxalic acid in the solution, $\%$.

We determined the correction factor for evaluating the corrosivity of canned products using the experimental scheme developed by us, which includes:

1) plotting the graphs of uniform and pitting corrosion upon interaction of tinplate with a two-component model medium containing citric acid and oxalic acid;

2) plotting graphs of uniform and pitting corrosion upon interaction of tinplate with tomato paste mixed with water;

3 ) calculation of corrosion parameters using formulas (1)-(6);

4) calculation of the correction factor using the formula:

$$
R=\frac{\bar{V}_{\mathrm{m}}}{\bar{V}_{\mathrm{p}}}
$$

where $R$ is the correction factor; 
$\bar{V}_{\mathrm{m}}$ is the average steady-state rate of uniform $\left(K_{\mathrm{m}}\right)$ or pitting $\left(P_{\mathrm{m}}\right)$ corrosion in the model medium;

$\bar{V}_{\mathrm{p}}$ is the average steady-state rate of uniform $\left(K_{\mathrm{p}}\right)$ or pitting $\left(P_{\mathrm{p}}\right)$ corrosion in the tomato paste.

\section{Results and Discussion}

Figures 1 and 2 show the plots of the tinplate I corrosion kinetics on exposure to oxalic acid solutions.

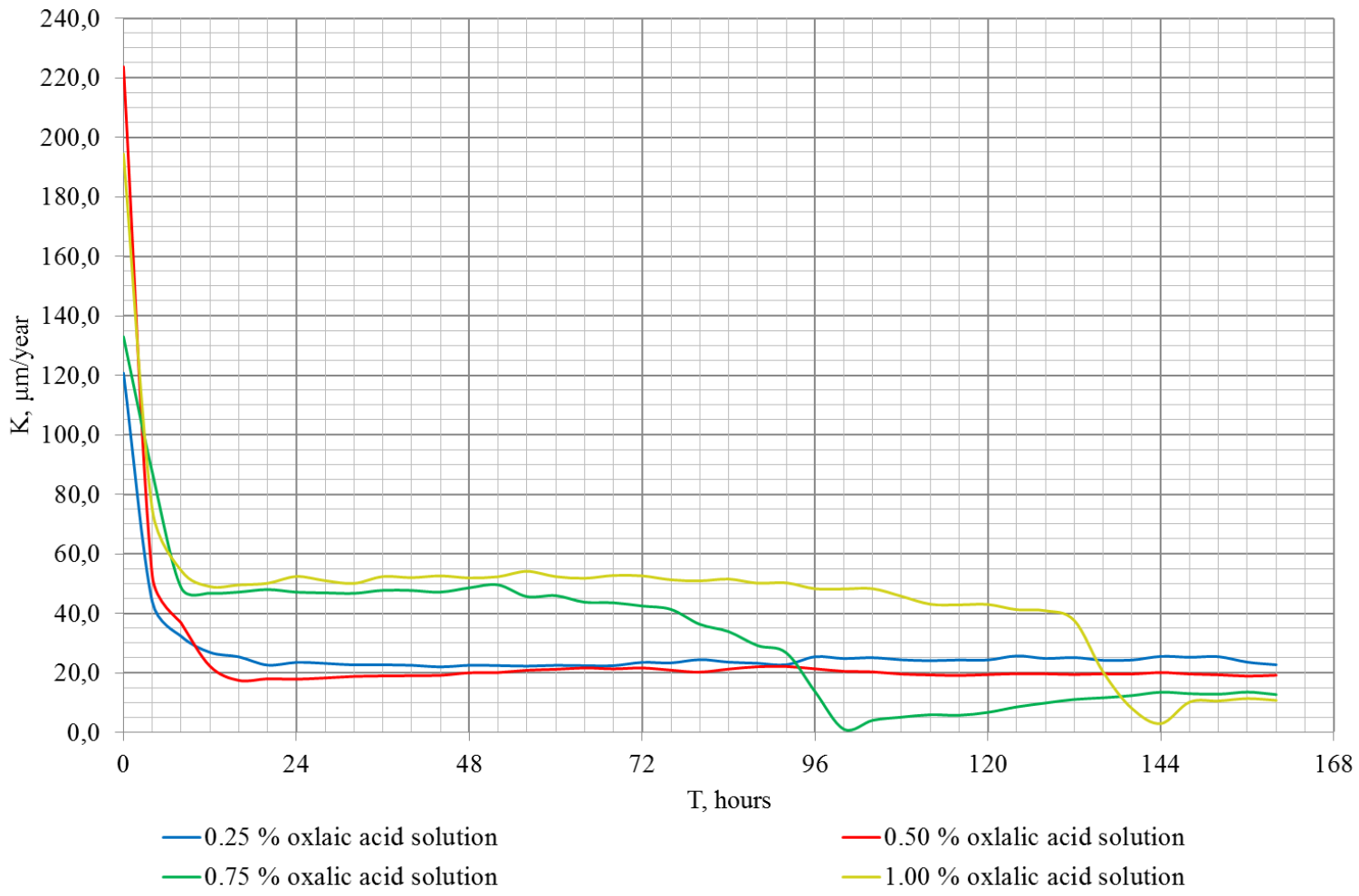

Figure 1. Kinetics of tinplate I uniform corrosion rate on exposure to oxalic acid solutions.

As it can be seen from Figures 1 and 2, the maximum rates of uniform and pitting corrosion of tinplate I are observed at the beginning of the experiment in $0.25 \%$ and $0.50 \%$ oxalic acid solutions, which gradually decrease to the steady-state values. This behavior of the process is explained by the accumulation of insoluble and poorly soluble corrosion products-mainly tin oxalates-on the metal surface. During the first 4-12 hours, the deposition rate of insoluble corrosion products exceeds the dissolution rate of the passivating chromate layer, which explains the decrease in the corrosion rate. In $0.75 \%$ and $1.00 \%$ oxalic acid solutions, the maximum uniform corrosion rate is observed at the beginning of the experiment, which gradually decreases to $48-51 \mu \mathrm{m} /$ year. During the next $2-3$ days, the corrosion rate does not change, and then it decreases to a minimum value. Then the corrosion rate increases and a steady-state mode is established. The pitting corrosion rate at the 
beginning of the experiment has a maximum value and gradually decreases to 5-7 $\mu \mathrm{m}$ /year. During the next 3-4 days, the value does not change, and then it increases and a steady-state mode is established. This behavior is explained by the deposition of oxalates in the initial period followed by their partial dissolution due to the formation of $\left[\mathrm{Fe}\left(\mathrm{C}_{2} \mathrm{O}_{4}\right)_{3}\right]^{3-}$ and $\left[\mathrm{Sn}\left(\mathrm{C}_{2} \mathrm{O}_{4}\right)_{2}\right]^{2-}$ complex ions [21].

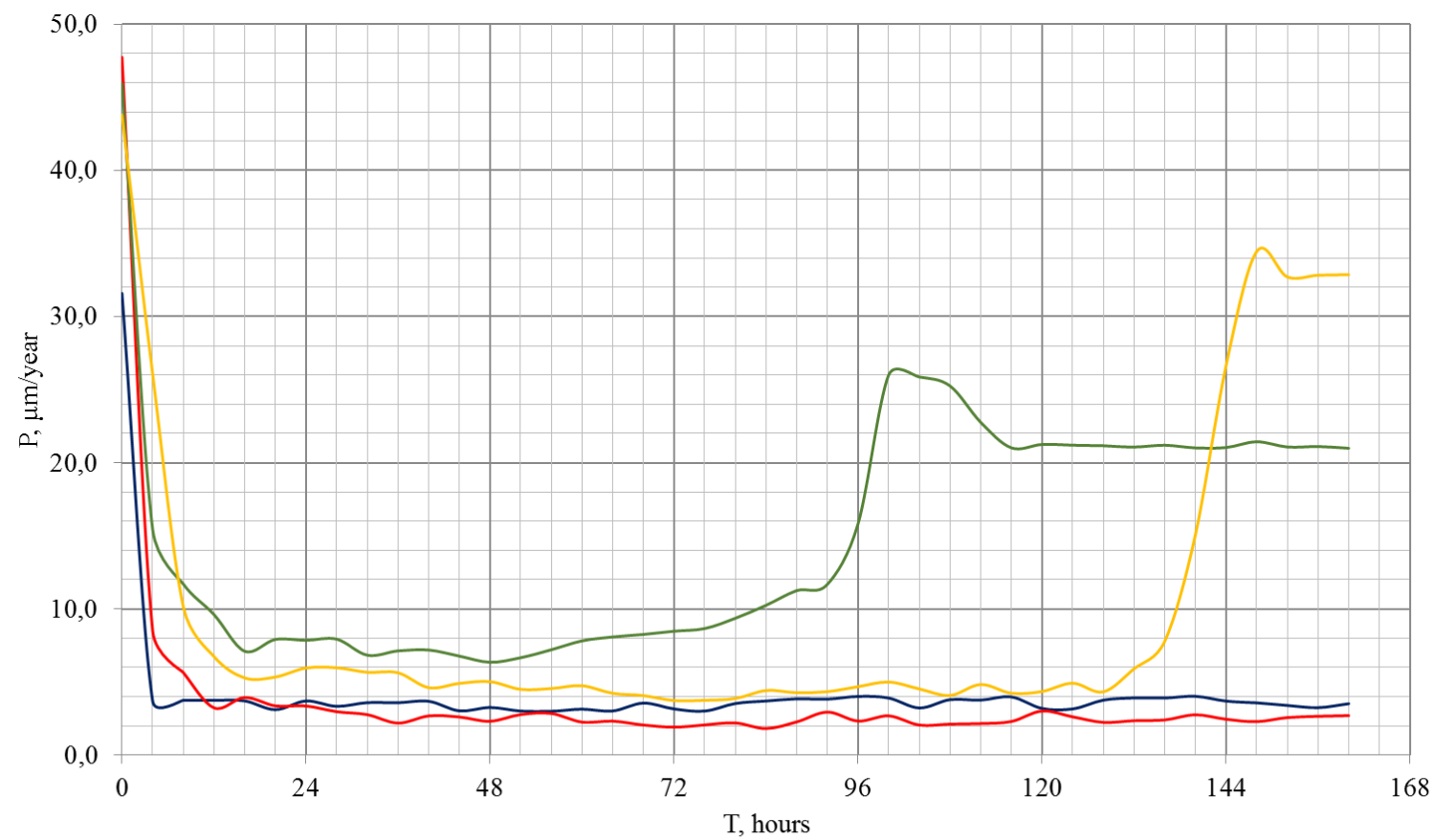

$-0.25 \%$ oxalic acid solution $-0.50 \%$ oxlaic acid solution $-0.75 \%$ oxalic acid solution $-1.00 \%$ oxalic acid solution

Figure 2. Kinetics of tinplate I pitting corrosion rate on exposure to oxalic acid solutions.

The parameters of the tinplate I corrosion process in oxalic acid solutions are shown in Table 3.

Table 3. Parameters of the tinplate I corrosion process in oxalic acid solutions.

\section{Corrosion}

\begin{tabular}{ccccc} 
Oxalic acid mass & \multicolumn{2}{c}{ Uniform } & \multicolumn{2}{c}{ Pitting } \\
\cline { 2 - 5 } & $\overline{\boldsymbol{K}}_{\mathrm{st}} \pm \boldsymbol{S}_{\mathbf{K}}, \boldsymbol{\mu \mathbf { m }} / \mathbf{y e a r}$ & $\boldsymbol{n}$ & $\overline{\boldsymbol{P}}_{\text {st }} \pm \boldsymbol{S}_{\mathbf{P}}, \boldsymbol{\mu} \mathbf{m} / \mathbf{y e a r}$ & $\boldsymbol{n}$ \\
\hline 0.25 & $23.83 \pm 1.24$ & 38 & $3.53 \pm 0.32$ & 40 \\
0.50 & $19.87 \pm 1.17$ & 37 & $2.54 \pm 0.45$ & 38 \\
0.75 & $12.56 \pm 0.86$ & 8 & $21.26 \pm 0.47$ & 13 \\
1.00 & $10.71 \pm 0.49$ & 4 & $32.80 \pm 0.08$ & 4 \\
\hline
\end{tabular}


Table 3 shows that in 0.25 and $0.50 \%$ oxalic acid solutions, the steady-state uniform corrosion rates are 7-7.5 times higher than the steady-state pitting corrosion rates, i.e., the process is characterized as uniform corrosion.

In 0.75 and $1.00 \%$ oxalic acid solutions after a steady-state mode is established, the pitting corrosion rate is 1.5-3 times higher than the uniform corrosion rate, i.e., the process is characterized as uniform corrosion with partial pitting.

Based on the average steady-state values of the uniform corrosion rate, the $0.25 \%$ oxalic acid solution has the highest corrosivity toward tinplate I, while the $1.00 \%$ solution has the lowest corrosivity (Table 3). This is due to a decrease in the dissociation degree of molecules with an increase in the concentration of the acid in the solution, which follows from the Ostwald's dilution law.

Figures 3 and 4 show the plots of tinplate I corrosion kinetics in citric acid solutions. One can see that in $0.25-1.25 \%$ citric acid solutions, the maximum uniform and pitting corrosion rates are observed at the beginning of the experiments and gradually decrease to steady-state values, which is associated with the deposition of insoluble tin and iron hydroxides on the metal surface that are formed due to ion exchange. At the same time, in the first 4-12 hours, the deposition rate of insoluble corrosion products is higher than the dissolution rate of the passivating chromate layer. For $1.50 \%$ solution at the beginning of the experiment, the uniform corrosion rate increases from 16.71 to $50.10 \mu \mathrm{m} / \mathrm{year}$, then gradually decreases to a stationary value. This process kinetics is explained by the fact that the dissolution rate of the passivation film (chromium compounds) in the first 4 hours is higher than the precipitation rate of insoluble corrosion products, and then the deposition rate of insoluble corrosion products increases.

The parameters of the tinplate I corrosion process when interacting with citric acid solutions are shown in Table 4.

Table 4. Parameters of the tinplate I corrosion process in citric acid solutions.

\section{Corrosion}

\begin{tabular}{ccccc}
$\begin{array}{c}\text { Citric acid mass } \\
\text { fraction, } \%\end{array}$ & \multicolumn{2}{c}{ Uniform } & \multicolumn{2}{c}{ Pitting } \\
\cline { 2 - 5 } & $\overline{\boldsymbol{K}}_{\mathrm{st}} \pm \boldsymbol{S}_{\mathbf{K}}, \boldsymbol{\mu} \mathbf{m} / \mathbf{y e a r}$ & $\boldsymbol{n}$ & $\overline{\boldsymbol{P}}_{\text {st }} \pm \boldsymbol{S}_{\mathbf{P}}, \boldsymbol{\mu} \mathbf{m} / \mathbf{y e a r}$ & $\boldsymbol{n}$ \\
\hline 0.25 & $22.42 \pm 0.99$ & 37 & $2.57 \pm 0.27$ & 36 \\
0.50 & $26.56 \pm 0.62$ & 37 & $3.93 \pm 0.21$ & 34 \\
0.75 & $18.94 \pm 0.97$ & 38 & $1.78 \pm 0.17$ & 35 \\
1.00 & $17.42 \pm 1.10$ & 37 & $1.52 \pm 0.14$ & 33 \\
1.25 & $17.78 \pm 0.68$ & 37 & $2.53 \pm 0.23$ & 38 \\
1.50 & $18.21 \pm 0.71$ & 33 & $2.39 \pm 0.15$ & 35 \\
\hline
\end{tabular}




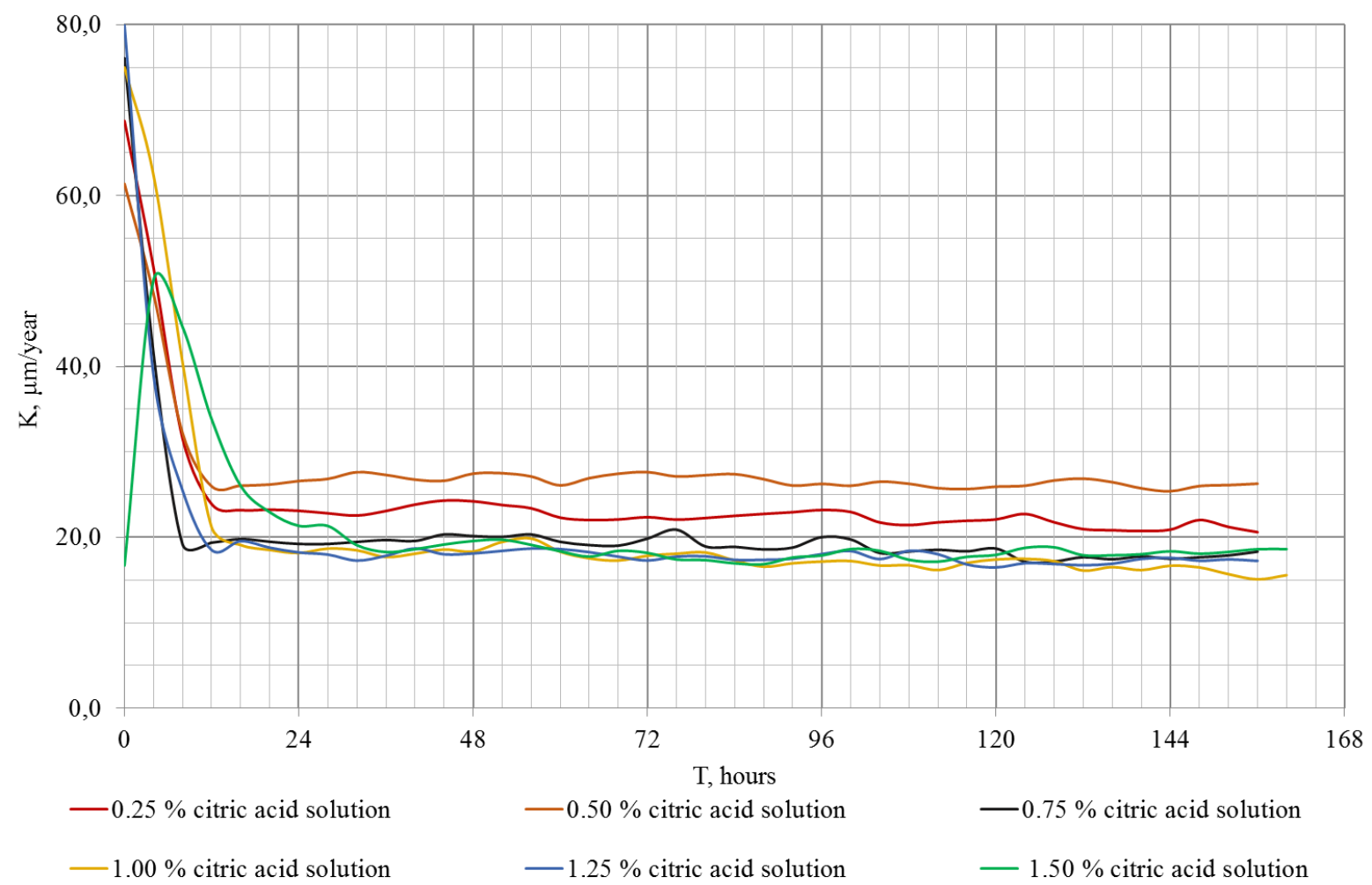

Figure 3. Kinetics of tinplate I uniform corrosion rate in citric acid solutions.

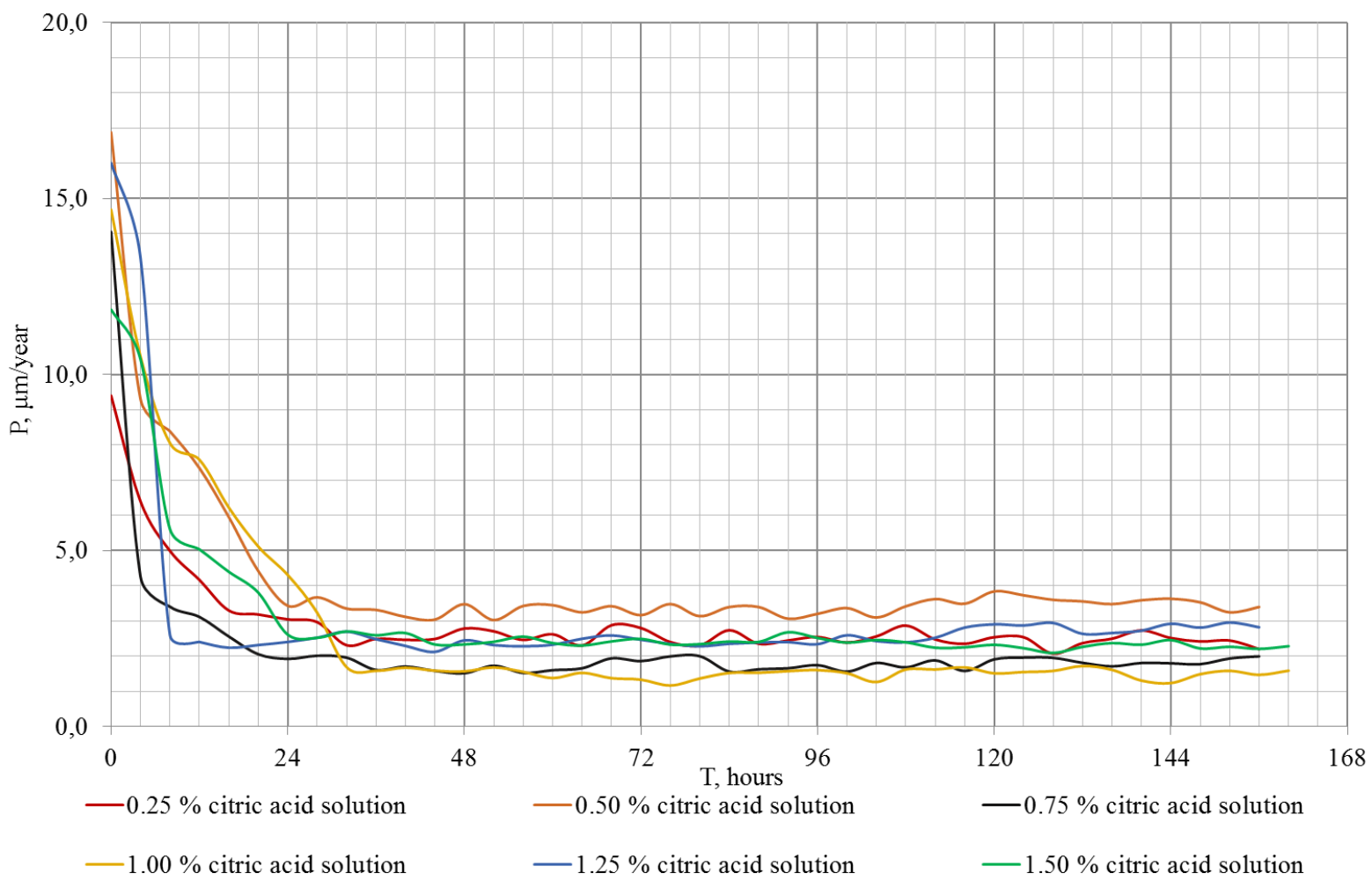

Figure 4. Kinetics of tinplate I pitting corrosion rate in citric acid solutions. 
Table 4 shows that the steady-state values of uniform corrosion rates in citric acid solutions are 7-11 times higher than the steady-state pitting corrosion rates, i.e., the process is characterized as uniform corrosion.

Based on the average steady-state uniform corrosion rates, the greatest corrosivity toward tinplate I is shown by $0.50 \%$ citric acid solution. In $0.75 \%-1.50 \%$ solutions, the steady-state uniform corrosion rate practically does not change with an increase in concentration, which is associated with a decrease in the degree of acid dissociation in the solution [22].

Based on the experimental values of uniform and pitting corrosion rates obtained in single-component solutions (Tables 3 and 4), we calculated the additive values (Table 5).

Table 5. Calculated additive values of uniform and pitting corrosion rates.

\begin{tabular}{|c|c|c|c|}
\hline \multirow{2}{*}{ No. } & \multirow{2}{*}{ Corrosive media } & \multicolumn{2}{|c|}{ Additive value of corrosion rate, $\mu \mathrm{m} /$ year } \\
\hline & & Uniform, $K_{\mathbf{a}}$ & Pitting, $P_{\text {a }}$ \\
\hline 1 & $0.25 \%$ citric acid $+0.25 \%$ oxalic acid & 23.13 & 3.05 \\
\hline 2 & $0.25 \%$ citric acid $+0.50 \%$ oxalic acid & 20.72 & 2.55 \\
\hline 3 & $0.25 \%$ citric acid $+0.75 \%$ oxalic acid & 15.03 & 16.59 \\
\hline 4 & $0.25 \%$ citric acid $+1.00 \%$ oxalic acid & 13.05 & 26.75 \\
\hline 5 & $0.50 \%$ citric acid $+0.25 \%$ oxalic acid & 25.65 & 3.08 \\
\hline 6 & $0.50 \%$ citric acid $+0.50 \%$ oxalic acid & 23.22 & 3.24 \\
\hline 7 & $0.50 \%$ citric acid $+0.75 \%$ oxalic acid & 18.16 & 14.33 \\
\hline 8 & $0.50 \%$ citric acid $+1.00 \%$ oxalic acid & 15.99 & 23.18 \\
\hline 9 & $0.75 \%$ citric acid $+0.25 \%$ oxalic acid & 20.16 & 2.22 \\
\hline 10 & $0.75 \%$ citric acid $+0.50 \%$ oxalic acid & 19.33 & 2.08 \\
\hline 11 & $0.75 \%$ citric acid $+0.75 \%$ oxalic acid & 15.75 & 11.52 \\
\hline 12 & $0.75 \%$ citric acid $+1.00 \%$ oxalic acid & 14.24 & 19.51 \\
\hline 13 & $1.00 \%$ citric acid $+0.25 \%$ oxalic acid & 18.70 & 1.92 \\
\hline 14 & $1.00 \%$ citric acid $+0.50 \%$ oxalic acid & 18.24 & 1.86 \\
\hline 15 & $1.00 \%$ citric acid $+0.75 \%$ oxalic acid & 15.34 & 9.98 \\
\hline 16 & $1.00 \%$ citric acid $+1.00 \%$ oxalic acid & 14.07 & 17.16 \\
\hline 17 & $1.25 \%$ citric acid $+0.25 \%$ oxalic acid & 18.79 & 2.70 \\
\hline 18 & $1.25 \%$ citric acid $+0.50 \%$ oxalic acid & 18.38 & 2.53 \\
\hline 19 & $1.25 \%$ citric acid $+0.75 \%$ oxalic acid & 15.82 & 9.55 \\
\hline 20 & $1.25 \%$ citric acid $+1.00 \%$ oxalic acid & 14.64 & 15.98 \\
\hline 21 & $1.50 \%$ citric acid $+0.25 \%$ oxalic acid & 19.01 & 2.55 \\
\hline
\end{tabular}


No. Corrosive media

Additive value of corrosion rate, $\mu \mathrm{m} / \mathrm{year}$

\begin{tabular}{lccc} 
No. & Corrosive media & Uniform, $\boldsymbol{K} \mathbf{a}$ & Pitting, $\boldsymbol{P} \mathbf{a}$ \\
\cline { 3 - 4 } & & 18.63 & 2.43 \\
22 & $1.50 \%$ citric acid $+0.50 \%$ oxalic acid & 16.33 & 8.68 \\
23 & $1.50 \%$ citric acid $+0.75 \%$ oxalic acid & 15.21 & 14.55 \\
\hline
\end{tabular}

Since canned products in metal packaging have long shelf lives, it is advisable to use the most corrosive model media for the corrosion tests. For this reason, we selected the following two-component corrosive media:

- $0.25 \%$ citric acid $+0.25 \%$ oxalic acid;

- $0.25 \%$ citric acid $+0.50 \%$ oxalic acid;

- $0.50 \%$ citric acid $+0.25 \%$ oxalic acid;

- $0.50 \%$ citric acid $+0.50 \%$ oxalic acid.

Figures 5 and 6 show the plots of tinplate I corrosion kinetics in the two-component solutions.

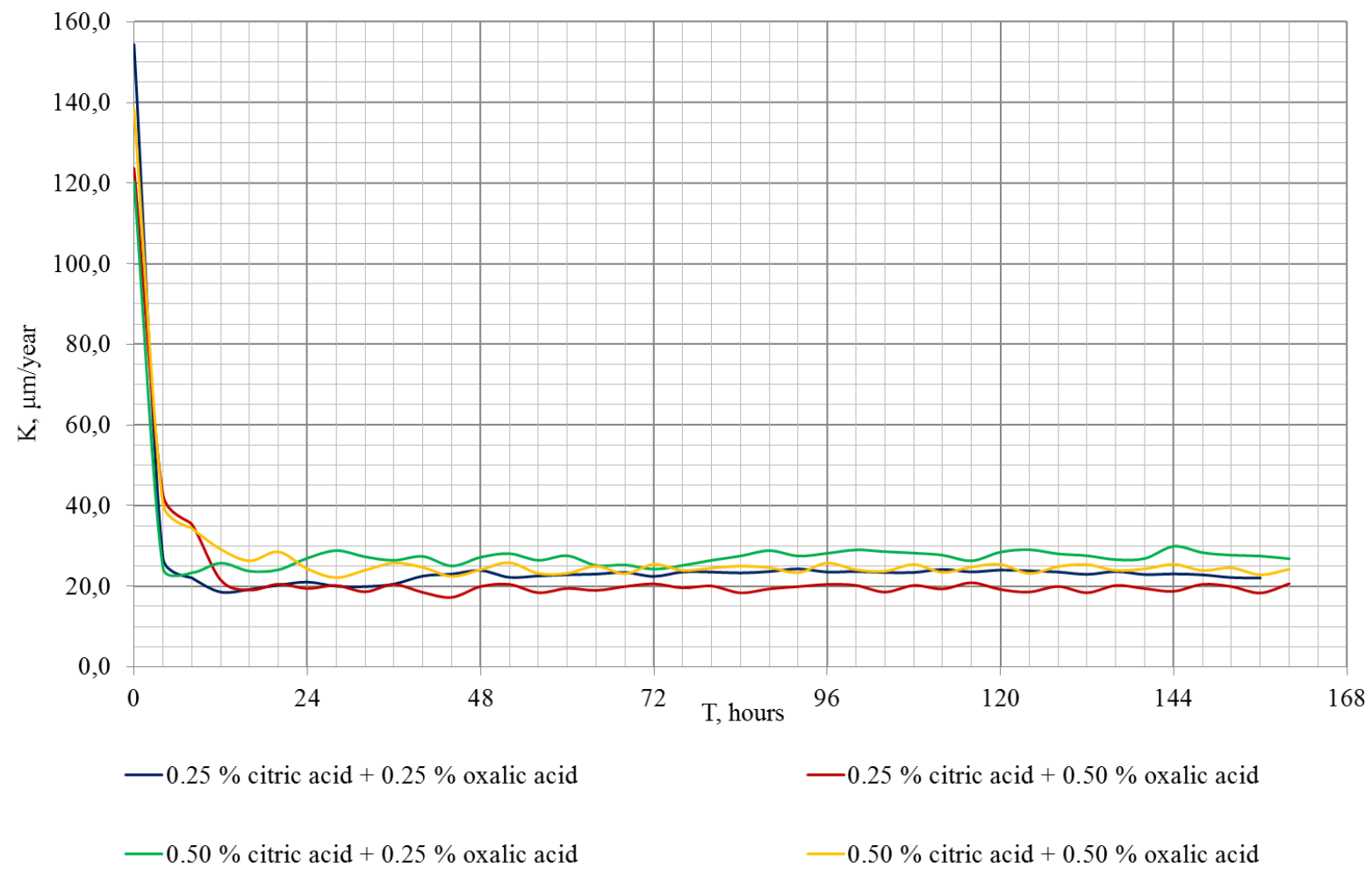

Figure 5. Kinetics of tinplate I uniform corrosion rate in two-component solutions. 


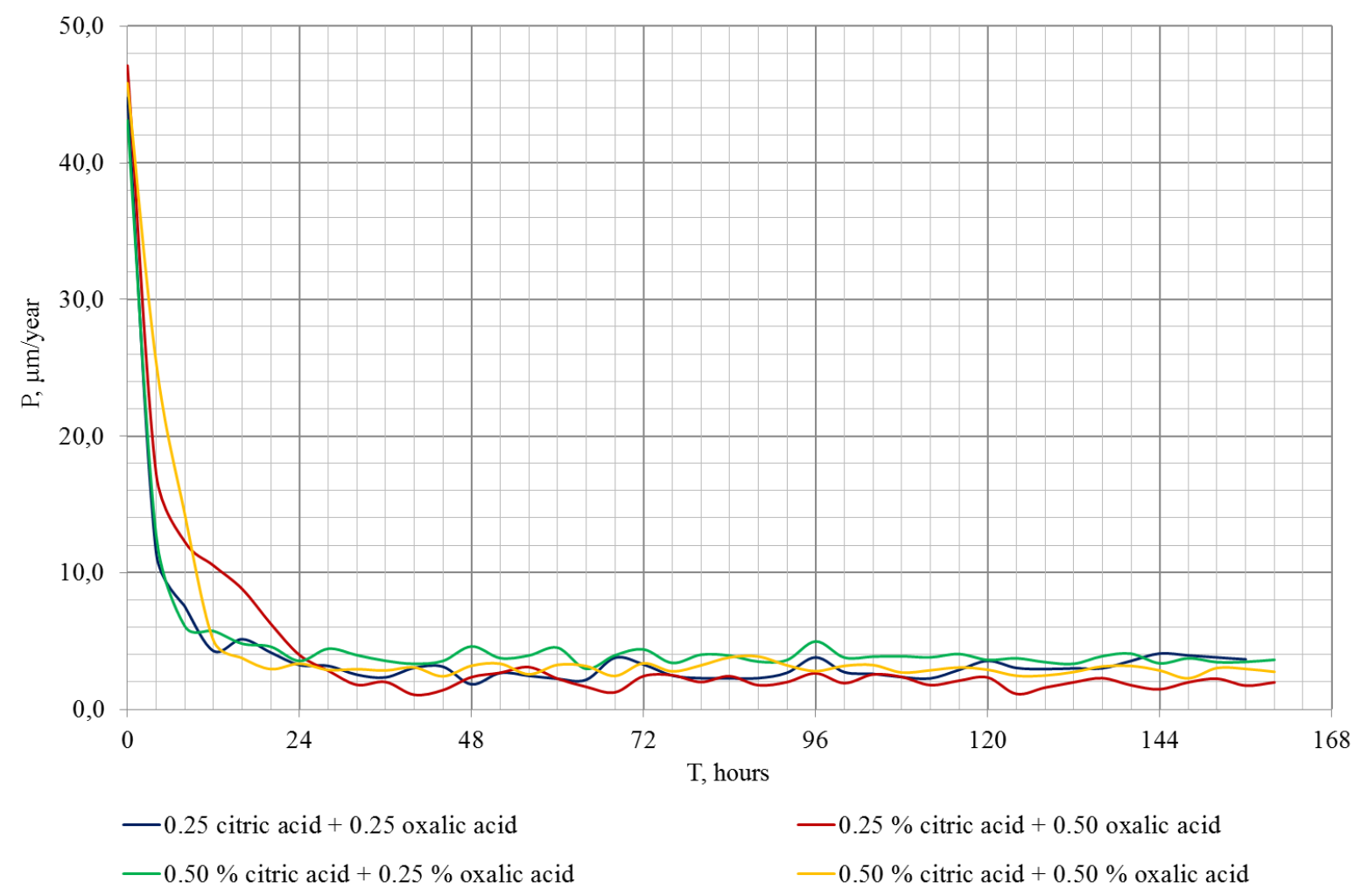

Figure 6. Kinetics of tinplate I pitting corrosion rate in two-component solutions.

Figures 5 and 6 show that at the beginning of the experiment, the uniform and pitting corrosion rates have the maximum values, the steady-state mode is established in 4 to 28 hours, i.e., the kinetics of the corrosion rate is similar to the process kinetics in the singlecomponent solutions.

The parameters of the tinplate I corrosion process in two-component solutions are shown in Table 6.

Table 6. Parameters of the tinplate I corrosion process in two-component solutions.

\section{Corrosion}

Corrosive media

\begin{tabular}{cccc}
\hline Uniform & \multicolumn{2}{c}{ Pitting } \\
\hline$\overline{\boldsymbol{K}}_{\mathrm{st}} \pm \boldsymbol{S}_{\mathbf{K}}, \boldsymbol{\mu \mathbf { m }} / \mathbf{y e a r}$ & $\boldsymbol{n}$ & $\overline{\boldsymbol{P}}_{\mathrm{st}} \pm \boldsymbol{S}_{\mathbf{P}}, \boldsymbol{\mu \mathbf { m }} / \mathbf{y e a r}$ & $\boldsymbol{n}$ \\
\hline $22.58 \pm 1.44$ & 38 & $2.91 \pm 0.61$ & 34 \\
$19.56 \pm 0.92$ & 38 & $2.04 \pm 0.48$ & 34 \\
$26.93 \pm 1.61$ & 40 & $3.85 \pm 0.45$ & 37 \\
$24.43 \pm 1.22$ & 37 & $3.00 \pm 0.38$ & 37 \\
\hline
\end{tabular}

$\frac{0.50 \% \text { c. a. }{ }^{1}+0.50 \%}{{ }^{1} \text { Citric acid; }{ }^{2} \text { oxalic acid. }}$ 
Table 6 shows that in two-component solutions, the average steady-state uniform corrosion rates are 7 to 10 times higher than the average steady-state values of the pitting corrosion rate, i.e., the process is characterized as uniform corrosion.

Furthermore, Tables 5 and 6 show that the average experimental values of uniform and pitting steady-state corrosion rates match the calculated additive values, taking into account the average square deviation. At the same time, the initial uniform and pitting corrosion rates are close to the values for the corresponding solutions of oxalic acid (Figures 1, 2, 5, 6). Thus, at the beginning of the experiment, the process kinetics is determined by the action of oxalic acid, while in the steady-state mode, by the additive effect.

Based on the calculated values of uniform corrosion additive rates (Table 5), a surface was built using the TableCurve 3D program (Figure 7).

We found by mathematical processing that the maximum steady-state uniform corrosion rate corresponded to the two-component medium containing $0.40 \%$ citric acid and $0.30 \%$ oxalic acid, i.e., such a medium is the most corrosive toward the tinplate.

To determine the correction coefficient, experiments were performed using tinplate with a tin coating of $5.5-5.7 \mathrm{~g} / \mathrm{m}^{2}$ (tinplate II) because this material is often used in the manufacture of cans.

Figure 8 shows the plots of tinplate II corrosion kinetics in the model medium containing $0.40 \%$ citric acid, $0.30 \%$ oxalic acid, and tomato paste mixed with water.

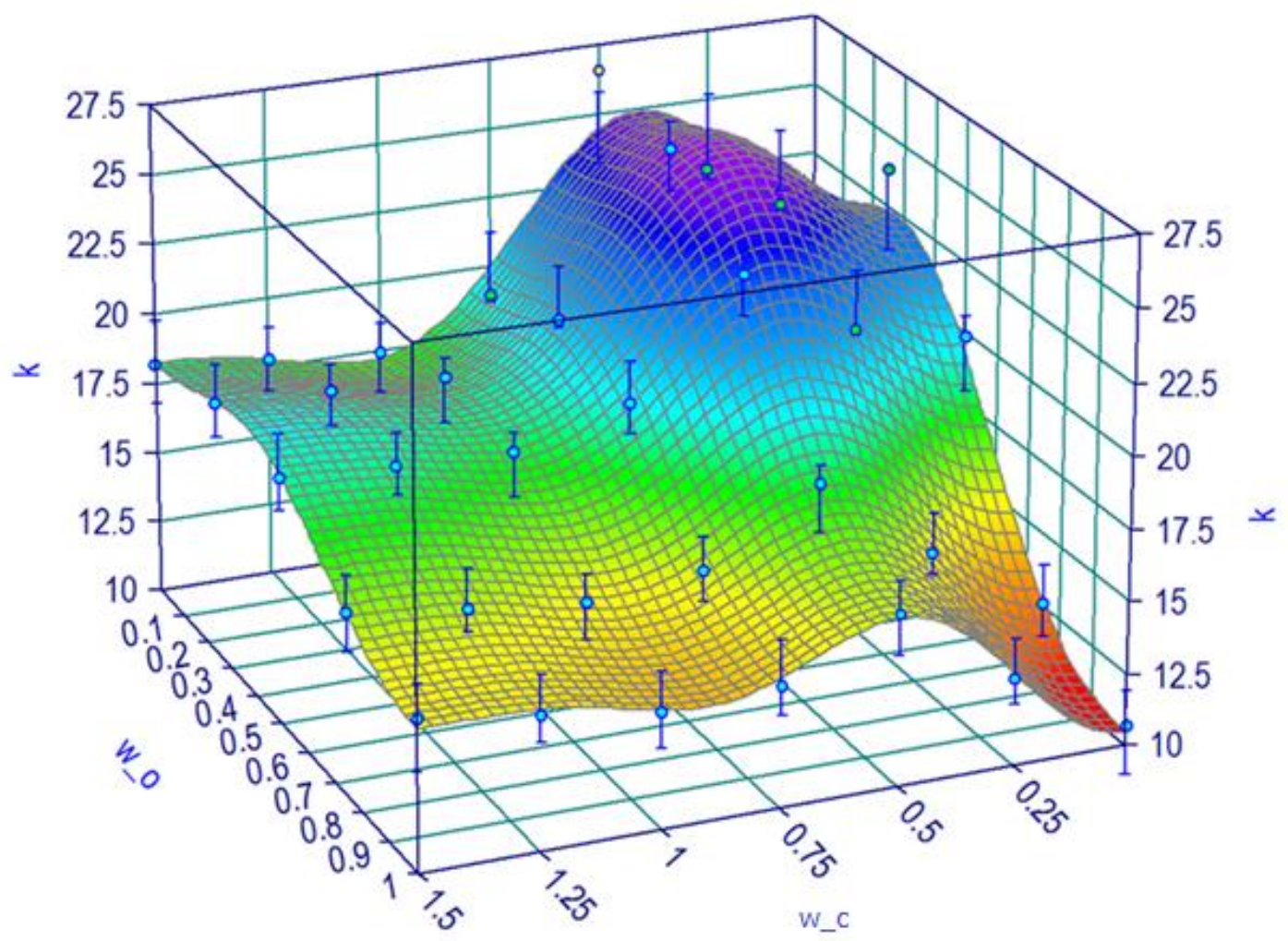

Figure 7. Additive values of steady-state uniform corrosion rate. $w_{-} c$ - citric acid mass fraction; $\mathrm{w} \_\mathrm{o}-$ oxalic acid mass fraction; $\mathrm{k}$ - uniform corrosion rate. 


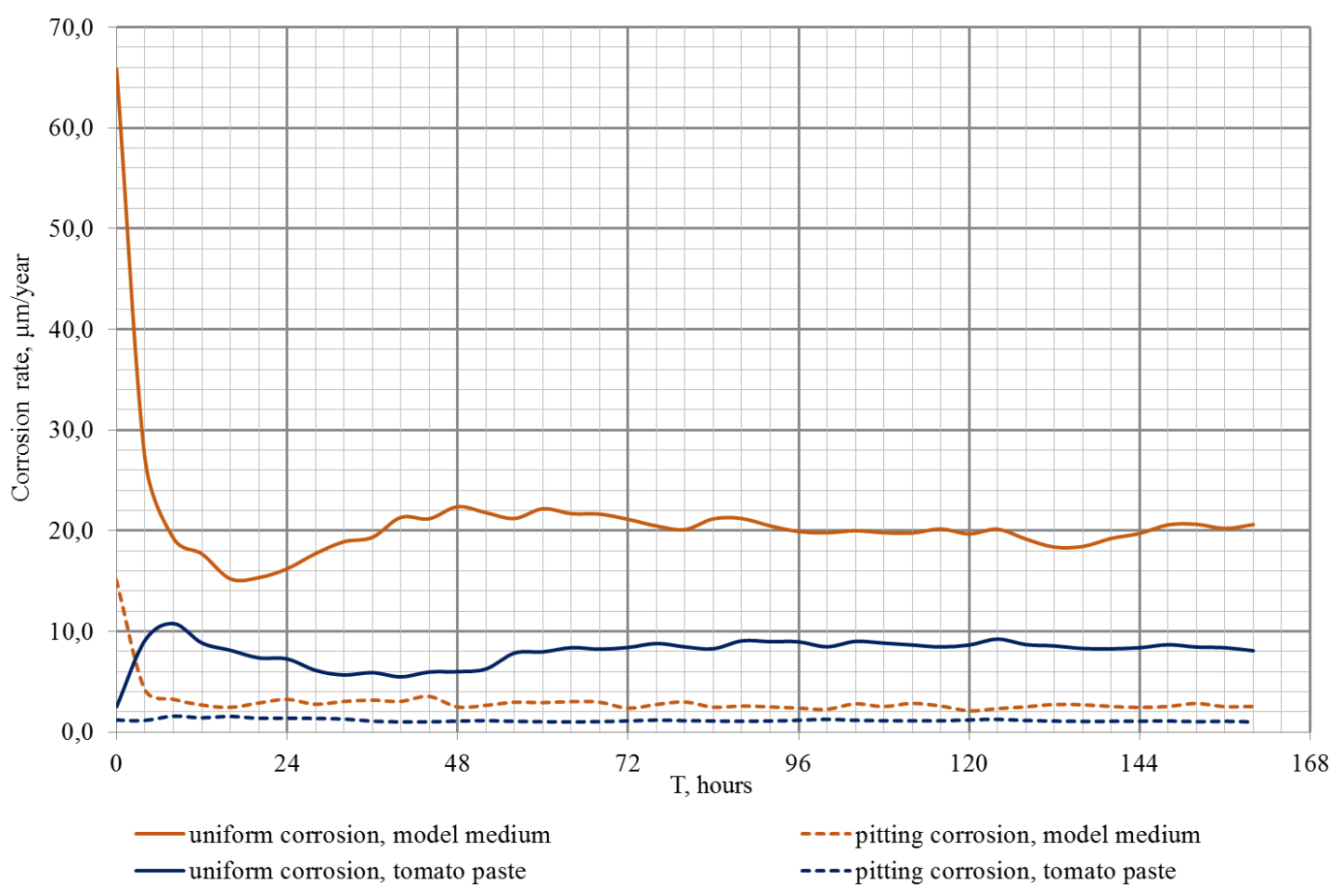

Figure 8. Kinetics of tinplate II corrosion rates.

When tinplate II interacts with the model medium, the corrosion process occurs as follows. At the beginning of the experiment, the corrosion rate has a maximum value ( $65.8 \mu \mathrm{m} /$ year), then it decreases, and after 20 hours from the beginning the minimum value is reached $(15.2 \mu \mathrm{m} /$ year). This is due to the deposition of low-solubility corrosion products, mainly tin oxalate and hydroxide, on the tinplate surface. This process predominates over the dissolution of the passivating chromate layer, hence the corrosion rate decreases. Over the next 20 hours, the corrosion rate increases, and the process becomes steady-state. The increase in the corrosion rate is explained by partial dissolution of the precipitate in the excess acid due to formation of complex ions, as well as an increase in the cathode area due to dissolution of tin and exposure of certain areas of the steel substrate [23, 24]. The transition of the corrosion process to a steady-state mode occurs when an equilibrium is reached between the deposition and dissolution of corrosion products.

When tinplate II interacts with tomato paste, the corrosion rate increases from 2.5 to $10.8 \mu \mathrm{m} /$ year within 8 hours from the beginning and then decreases to a minimum value $(5.5 \mu \mathrm{m} /$ year) over the next 32 hours. The increase in the corrosion rate in the initial period is probably due to the predominance of the dissolution of the chromate layer over the deposition of corrosion products. After the chromate layer is dissolved, the corrosion rate decreases due to deposition of tin oxalate and hydroxide on the tinplate surface. Over the next 16 hours, the corrosion rate increases, and the process becomes steady-state.

Table 7 shows the parameters of the tinplate II corrosion process in the model medium and in tomato paste. 
Table 7. Parameters of the tinplate II corrosion process.

\begin{tabular}{|c|c|c|c|c|c|}
\hline \multirow{3}{*}{ Corrosive media } & \multicolumn{4}{|c|}{ Corrosion } & \multirow{3}{*}{$\overline{\boldsymbol{K}}_{\mathrm{st}} / \overline{\boldsymbol{P}}_{\mathrm{st}}$} \\
\hline & \multicolumn{2}{|l|}{ Uniform } & \multicolumn{2}{|l|}{ Pitting } & \\
\hline & $\bar{K}_{\mathrm{st}} \pm S_{\mathrm{K}}, \mu \mathrm{m} /$ year & $n$ & $\bar{P}_{\mathrm{st}} \pm S_{\mathrm{P}}, \mu \mathrm{m} /$ year & $n$ & \\
\hline Model medium & $20.46 \pm 1.00$ & 31 & $2.73 \pm 0.31$ & 39 & 7.49 \\
\hline Tomato paste & $8.54 \pm 0.34$ & 27 & $1.12 \pm 0.07$ & 32 & 7.62 \\
\hline Correction factor, $R$ & 2.40 & - & 2.44 & - & - \\
\hline
\end{tabular}

Both in the model medium and in tomato paste, the process occurs uniformly: the average steady-state uniform corrosion rate is 7.5-7.6 times higher than the average steadystate pitting corrosion rate (Table 7). Also, Table 7 shows that tomato paste is less corrosive toward tinplate II than the model medium containing $0.40 \%$ citric acid and $0.30 \%$ oxalic acid. This is due to the inhibitory effect of pectin contained in tomato products [25].

\section{Conclusions}

1. In model media containing a mixture of citric and oxalic acids, the kinetics of the corrosion process is determined by two components: by the action of oxalic acid at the beginning of the process, and by the additive effect in the steady-state mode.

2. The kinetics of tinplate corrosion in tomato paste is similar to the kinetics of the process in the two-component model medium containing $0.4 \%$ citric acid and $0.3 \%$ oxalic acid.

3 . It is advisable to use a solution containing $0.40 \%$ citric acid and $0.30 \%$ oxalic acid as a model corrosive medium that simulates canned vegetables, with a correction factor of 2.4.

\section{References}

1. N.A.-G. Abdel-Rahman, Tin-plate Corrosion in Canned Foods, J. Global Biosci., 2015, 4, no. 7, 2966-2971.

2. E. Marengo, E. Mazzucco, E. Robotti, F. Gosetti, M. Manfredi and G. Calabrese, Characterization Study of Tomato Sauces Stored in Different Packaging Materials, Curr. Anal. Chem., 2017, 13, no. 3, 187-201. doi: 10.2174/1573411012666160504125330

3. L.P. Muniz, L.M.G. dos Santos, K.L.M. do Couto and S. do C. Jacob, Evaluation of metals in tomato sauces stored in different types of packaging, Food Sci. Technol., 2018, 38, no. 3, 383-389. doi: $10.1590 /$ fst. 27916

4. E.A. Andryushchenko and N.S. Tovstokora, Classification of fruit juices and fruit drinks according to their degree of corrosivity, Food Ind., 1986, no. 11, 48-49 (in Russian).

5. T.F. Platonova and A.N. Goren'kova, Investigation if the Corrosivity of Canned Fruits and Vegetables in Relation to White and Chrome Tin, Storage and Processing of Farm Products, 2009, no. 2, 35-38 (in Russian). 
6. V.A. Shavirin, N.S. Tovstokora, A.Sh. Chavchanidze, N.Yu. Timofeeva, A.Yu. Bazarkin and I.E. Rozenblat, Correlation between a scale of one to ten for corrosion resistance metallic packing materials and classification of canned food ranking in terms of its corrosion activity, Prakt. Protivokorroz. Zashch. (Practice of Anti-corrosion Protection), 2011, no. 1(59), 56-60 (in Russian).

7. G.L. Robertson, Food Packaging: Principles and Practice, Third Edition, CRC Press, 2012, 773.

8. F.W. Salt and J.G.N. Thomas, The anaerobic corrosion of tin in anthocyanin solutions and fruit syrups, J. Appl. Chem., 1957, 7, no. 5, 231-238. doi: 10.1002/jctb.5010070504

9. D. Tošković, M.B. Rajković and I. Čirić, Corrosion of Tin Plate in Brine Solutions, Russ. J. Appl. Chem., 2002, 75, no. 11, 1808-1811. doi: 10.1023/A:1022210103516

10. G.J. Benitez, P.A. Cirillo, M.G.L. Gines and W.A. Egli, Internal Corrosion in Tinplate Cans, 16th IAS Rolling Conference, 2006, San Nicolas, Argentina, 583-590.

11. K. Haruna, I.B. Obot, N.K. Ankah, A.A. Sorour and T.A. Saleh, Gelatin: A green corrosion inhibitor for carbon steel in oil well acidizing environment, J. Mol. Liq., 2018, 264, 515-525. doi: 10.1016/j.molliq.2018.05.058

12. S.A. Umoren, I.B. Obot, A. Madhankumar and Z.M. Gasem, Performance evaluation of pectin as ecofriendly corrosion inhibitor for X60 pipeline steel in acid medium: Experimental and theoretical approaches, Carbohydr. Polym., 2015, 124, 280-291. doi: 10.1016/j.carbpol.2015.02.036

13. S. Zor, The Effects of Benzoic Acid in Chloride Solutions on the Corrosion of Iron and Aluminum, Turk. J. Chem., 2002, 26, no. 3, 403-408.

14. M.A. Quraishi, F.A. Ansari and D. Jamal, Corrosion Inhibition of Tin by Some Amino Acids in Citric Acid Solution, Indian J. Chem. Technol., 2004, 11, 271-274.

15. D.V. Tošković, M.B. Rajković and D.D. Stanojević, Impact of Additives on Corrosion Rate of Cans Filled With Pieces of Apricot, J. Agric. Sci., 2005, 50, no. 1, 61-73. doi: 10.2298/JAS0501061T

16. A.R. Abdel-Moemin, Oxalate Content of Egyptian Grown Fruits and Vegetables and Daily Common Herbs, J. Food Res., 2014, 3, no. 3, 66-77. doi: 10.5539/jfr.v3n3p66

17. N.G. Anufriev, Application of polarization resistance and zero-resistance amperometry methods for investigation of corrosion metal conduct in aqueous media, Prakt. Protivokorroz. Zashch. (Practice of Anti-corrosion Protection), 2003, no. 4, 10-13 (in Russian).

18. N.G. Anufriev, New Possibilities of Applying the Linear Polarizing Resistance Method in Corrosion Research and Practice, Korroz.: Mater., Zashch. (Corrosion: Materials, Protection), 2012, no. 1, 36-43(in Russian).

19. E.A. Andryushchenko, Y.G. Kotlov, S.G. Polyakov, G.I. Robsman and N.S. Tovstokora, Evaluation of the corrosivity of preserving media by the polarization resistance method, Prot. Met., 1988, 23, no. 5, 636-638. 
20. A.N. Petrov, V.A. Shavirin, A.Y. Bazarkin and O.V. Bessarab, Determination of the Corrosion Resistance of the Inner Surface of Cans for Canned Foods, Food Ind., 2013, no. 6, 10-12 (in Russian).

21. Typical and specific reactions of the tin cations. URL: https://medlec.org/lek250007.html

22. R.K. Kvaratskhelia and E.R. Kvaratskhelia, About dissociation of weak two-and threebasic organic acids involved in the Krebs cycle, Elektrokhimiya (Electrochemistry), 2009, 45, no. 2, 235-238 (in Russian).

23. Y. Che, Z. Han, B. Luo, D. Xia, J. Shi, Z. Ga and J. Wang, Corrosion Mechanism Differences of Tinplate in Aerated and Deaerated Citric Acid Solution, Int. J. Electrochem. Sci., 2012, 7, 9997-10007.

24. A. Montanari and C. Zurlini, Influence of side stripe on the corrosion of unlacquered tinplate cans for food preserves, Packag. Technol. Sci., 2018, 31, no. 1, 15-25. doi: $10.1002 /$ pts. 2339

25. O.V. Bessarab and T.F. Platonova, Usage of food additives for improvement of the quality and safety of fruit canned food in metallic packaging, Vestnik VGUIT (Proceedings of VSUET), 2018, 80, no. 3, 170-175 (in Russian). doi: 10.20914/23101202-2018-3-170-175 